\title{
Assessment of the Psychological Wellbeing of Elderly Residing at Pooncheri Rural Community Area in Kancheepuram District, Tamilnadu, India
}

\author{
George Fernandez $\mathbf{A}^{\mathbf{1}}$, Janagiraman $\mathbf{N}^{\mathbf{1}}$, Shalini $\mathbf{M}^{\mathbf{1}}$, Vinitha $\mathbf{R}^{\mathbf{1}}$, Metha ${ }^{\mathbf{2}}$ \\ ${ }^{1}$ B.Sc (NURSING) Student, ${ }^{2}$ Nursing Associate Professor, Chettinad College of Nursing, Chettinad Academy of \\ Research and Education, Tamilnadu, India
}

\begin{abstract}
A descriptive Study on Assessment of the psychological wellbeing residing in pooncheri rural community area in kancheepuram (dist.), Tamil Nadu India. The objectives are to assess psychological wellbeing of elderly people. To find out the association between levels of psychological wellbeing of elderly people and selected demographic variables of elderly people. The sampling technique was non-probability, purposive sampling technique with 111 samples of elderly people and WHO standardized psychological wellbeing scale were used to assess psychological wellbeing of elderly. The demographic variables Performa, were used to collect data. The data collection tools were validated and reliability was established. The data collection for the main study was done. The collected data was tabulated and analyzed, using descriptive and inferential statistics. Majority of elderly $71.2 \%$ had adequate, $28.8 \%$ had moderate wellbeing, There no poor wellbeing. The psychological wellbeing mean value is57.34.
\end{abstract}

Key Words: Elderly, Wellbeing, rural community area, psychological wellbeing scale .

\section{Introduction}

Aging is an unavoidable developmental phenomenon bringing along several changes in the physical, psychological, hormonal and social conditions. Age has been viewed, as a problematic period of one's life and this is correct to some extent. Aged become increasingly dependent on others. As a man grows, his reduced activities, income and consequent decline in the position of the family and society make his life more vulnerable. ${ }^{(1)}$

The population expectation made by the UNESCO indicates that the percentage of the aged above 60 are likely to go up from 7.1 percent in 1991 to 12.3 percent in 2025 in India alone. Therefore, need to be paid proper observation to the quality of life of older persons. In almost all the countries of the world, elderly women be more numerous than elderly men. Rapid aging trends present new provocation to the government, families and the elderly themselves. ${ }^{(2)}$

The difficulty of elderly females has become a social problem in Indian society. The changes in the demographic structure during the last few decades in developing countries have made the aged socially more noticeable section. Moreover, modern society has faced a vast modification due to breaking up of the joint family system, technological upraising and attitude of the younger age group towards old age. All these have move on to the problems of the elderly, particularly women. The economic insufficiency of the nuclear family is resulting in the neglect of its members. The traditional roles are slowly being replaced with unimportant roles after retirement. ${ }^{(3)}$

The problems consummate by elderly are more acute, who are economically dependent solely on the families. In the advancing age, when the aged loose friends, power influence, job status, income, health, etc. bring a host of problems connected to physical, economic, social and psychological aspects. The elderly is a essential phase where the physiological, psychological and socio-cultural changes in the elderly present to developing anxiety. ${ }^{(4)}$ 
Modernization and globalization have disintegrated the Indian family system and elders are forced to stay in old age homes. In some cases, elderly members of relatively rich families or aged persons who have nobody to look after takes shelter in old age homes. The elderly lives in these homes merely in terms of existence to complete the last phase of the lives. ${ }^{(5)}$

Elderly is generally the chronological age, a universal phenomenon and a challenge to everyone, who reaches it irrespective of occupation, skill or learning. The world is rapidly aging: the number of people aged 60 and over as segment of the universal population will double from $11 \%$ in 2006 to $22 \%$ by 2050 . As per the WHO recommendation people 60-74 years of age are called elderly and those between 75 and $85+$ years of age as old. By then, there will be older people than children (aged 0-14) in the population for the first time in human history. ${ }^{(6)}$

\section{Objectives}

. To assess the Psychological wellbeing of elderly.

To find out the association between psychological wellbeing of elderly with the selected demographic variables.

\section{Hypothesis:}

- H1: There was significant level of Psychological wellbeing among Elderly.

- H 2: There was significant association between Psychological wellbeing with their selected demographic variable.

\section{Research Methodology}

In this study Quantitative research approach and, Descriptive research design adopted. Non-experimental descriptive research design was used for the present study. Standardized WHO Psychological wellbeing scale was used to assess the psychological wellbeing of elderly and Structured questionnaire to assess demographic variables of Elderly Peoples residing in a selected rural community area who fulfills the given criteria were selected as a sample.

\section{Sampling Criteria:}

\section{A. Inclusion Criteria}

The inclusion criteria were as follows:

- Elderly sample who living in a selected community area.

- Elderly with the age group 60 years and above

\section{B. Exclusion Criteria}

The exclusion criteria as follows:

- Elderly who are having mental illness.

- Elderly who are not willing to participate.

\section{Method of Data Collection:}

In this present study the researcher distributed questionnaires to the samples. The samples were instructed to fill the data. Each sample took $30 \mathrm{~min}$ for completion of their data. Data collected over a period of one week(from 22-4-2018 to 27-4-2018).The convient sampling technique adopted. The data was collected in pooncheri village, kanchepuram district tamilnadu, India the total sample is 111 . Among the total samples 51 were male and 60 were female.

\section{Research Tool:}

There are Two sections (A\&B) in Research tool, in Section A consist of Self structured questionnaire consists of 9 questions to asses demographic variables\& Section B consist of WHO psychological wellbeing scale consist of 18 items and consists of serious of statements reflecting the six areas of psychological wellbeing autonomy, environment, mastery, personal growth, positive relation with others, purpose in life and acceptance.

\begin{tabular}{|c|l|}
\hline \multicolumn{2}{|l|}{ SCORING \& INTERPRETATION: } \\
\hline SCORE & LEVEL OF WELLBEING \\
\hline $61-90 \%$ & Adequate knowledge \\
\hline $31-60 \%$ & Moderate knowledge \\
\hline $18-30 \%$ & Poor knowledge \\
\hline
\end{tabular}




\section{Data Collection Procedure:}

The written informed consent was obtained from the research participants. Permission letter was obtained from the HOD of Mental Health Nursing, UG committee and Human Ethical committee.
Formal permission obtained from the management and the department of community medicine.

Descriptive statistics like frequency distribution, percentage, mean, standard deviation \& inferential statistics like chi square used to analyse the data.

Collected data tabulated and analysed.

\begin{tabular}{|l|l|l|l|}
\hline \multicolumn{4}{|l|}{ Frequency and percentage distribution of Psychological wellbeing of elderly } \\
\hline S.NO & Level of Wellbeing & Frequency & Percentage \\
\hline 1 & Adequate & 79 & $71 \%$ \\
\hline 2 & Moderate & 32 & $29 \%$ \\
\hline 3 & Poor & 0 & $0 \%$ \\
\hline
\end{tabular}

$(\mathrm{N}=111)$

\section{Result}

The study findings revealed that,

$\varnothing$ In previous study on assessment of Psychological wellbeing result shows that;

The study investigated the effect of intergeneration social support on the subjective well-being of 429 elderly participants. Results suggested that intergeneration social support, self-esteem, and loneliness were significantly correlated to subjective well-being. Structural equation modeling indicated that self-esteem and loneliness partially mediated the effect of intergeneration social support on subjective well-being. These findings provided insights into the effect of intergeneration social support on the subjective well-being of the elderly,(Qian Tian Sep 9 , 2014)

Relationship with children and the psychological well-being of the elderly Litha Almira, Lathifah Hanum, Adhityawarman Menaldi the study is results showed no correlation between the positive qualities of the relationship and psychological well-being $(r=0.092, p>0.01)$. However, the negative qualities of the relationship were negatively correlated with psychological well-being $(\mathrm{r}=-0.335, \mathrm{p}<0.01)$ This study employed convenience sampling and to reach 102 elderly participants.

Our study result reveals that in assessing the level of wellbeing showed that the mean score 57.34, mean $\%$ 64\% and standard deviation 6.59 Psychological wellbeing of elderly. Maximum score for Psychological welleing were Adequete 79(71\%), moderate32(29\%).

Distribution of demographic characteristics of elderly said that the majority elderly was in the age group of $60-65$ years $50(45 \%)$, most of elderly was female $60(54 \%)$, majority of elderly got the primary education $51(46 \%)$, most of the elderly people previous occupational status was daily wage workers $44(40 \%)$, majority of the elderly was Hindus 94(85\%). The language spoken by the elderly was Tamil 108(97\%), they are living in the nuclear family93(108\%), majority of the people having own house $85(77 \%)$ and the less number of elderly getting pension21(19\%).

\section{Discussion}

Psychological wellbeing and the association factor in our study shows that:

The findings of the study revealed that there showed that there is significant association between the demographic variable $(\mathrm{P}=<0.005)$ and the gender and language, there is no significant association between 
demographic variables and psychological wellbeing among elderly in age, education, previous occupational status, religion, family, type of house and are they getting any pension.

\section{Conclusion}

On the basis of research, we concluded the Psychological wellbeing is majority of the elderly is have adequate wellbeing and minority of elderly having moderate wellbeing.

Source of Funding: By self-funding there no external source

\section{Conflict of Interest- Nil}

\section{References}

1. Tandon M. A study on psychological well-being among elderly. International Journal of Home Science. 2017;3(1):387-9.
2. Share of population over age of 60 in India projected to increase to $20 \%$ in 2050 - The Economic Times 3. Mehrotra N, Batish S. Assessment of problems among elderly females of Ludhiana city. Journal of Human Ecology. 2009 Dec 1;28(3):213-6.

4. Ingle GK, Nath A. Geriatric health in India: Concerns and solutions. Indian journal of community medicine: official publication of Indian Association of Preventive \& Social Medicine. 2008 Oct;33(4):214.

5. Kavita B, Bipin P, Geeta K. A Study to Assess the Availability of Basic Facilities For Inmates In Geriatric Home, Ahmedabad, Gujarat, India. National Journal of Community Medicine. 2012;3:408-13.

6. Mehrotra N, Batish S. Assessment of problems among elderly females of Ludhiana city. Journal of Human Ecology. 2009 Dec 1;28(3):213-6. 